\title{
Changes In Special Items And Future Firm Growth
}

Young Zik Shin, Sungkyunkwan University, South Korea Yong Gyu Lee, Sungkyunkwan University, South Korea

\begin{abstract}
This study examines the effect of changes in special items on future firm growth. We find that a decrease in special items reverses almost completely through one-year-ahead earnings, whereas an increase in special items is positively associated with the next year's earnings growth. We also find that the information embedded in changes in special items is incremental to that of fundamental signals documented in the literature, thereby identifying changes in special items as an additional fundamental signal. Furthermore, we find that both an increase and a decrease in special items lead to decreases in future sales and net operating assets, suggesting an inverse U-shaped relation between changes in special items and growth in these measures. Overall, our findings underscore the importance of considering various growth measures in understanding the implication of changes in special items for future firm growth.
\end{abstract}

Keywords: Special Items; Growth; Earnings; Sales; Net Operating Assets

\section{INTRODUCTION}

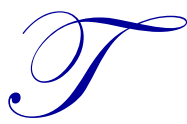

his paper investigates the effect of changes in special items on future firm growth. Special items are defined as “material events that arise from a firm's ongoing, continuing activities, but that are either unusual in nature or infrequent in occurrence, but not both (Revsine, Collins \& Johnson 2005, as cited in McVay 2006)." Prior research has focused on the implication of special items for future earnings and generally supports the view that special items are less persistent than other earnings components with respect to one-yearahead earnings (e.g., Fairfield, Sweeney \& Yohn 1996; Burgstahler, Jiambalvo \& Shevlin 2002). Some studies, however, have raised concerns about the predicted content of special items for future earnings because special items can reflect managers' strategic attempts to meet reporting benchmarks (e.g., Kinney \& Trezevant 1997; McVay 2006). Regardless of how special items affect future earnings, several significant issues remain unexplored, including the predictive content of changes in special items for future earnings growth and other growth measures, such as growth in sales and net operating assets, the latter of which is defined as a firm's operating assets minus operating liabilities. ${ }^{1}$

The literature on special items generally focuses on the implication of levels of large negative special items for future earnings. As a result, small and/or positive special items are often excluded from the analysis, although these items may also have nontrivial implications. Our focus on changes in special items not only addresses this problem but also accommodates a greater variety of scenarios that firms face by allowing for one more degree of freedom. This is relevant given the prior evidence that the incidence of non-zero special items has increased dramatically over time (e.g., Elliott \& Hanna 1996; Cready, Lopez \& Sisneros 2010). Furthermore, assuming that special items reflect either managers' reporting incentives or firms' underlying economics, one may get a better sense of firms' underlying circumstances by understanding the information embedded in changes in special items.

Moreover, examining the associations between changes in special items and other growth measures may provide further insight into the effect of special items on future operating performance. Because of the reversal of special items documented in the literature (e.g., Burgstahler et al. 2002; Frankel \& Roychowdhury 2007), the implication of

${ }^{1}$ Examples of operating assets include accounts receivable, inventory, and fixed assets. Examples of operating liabilities include accounts payable and accrued expenses. 
special items for future earnings is difficult to evaluate. In particular, even if special items lead to an increase in future earnings, this relation is difficult to interpret because managers can engage in opportunistic reporting behavior such as "earnings baths." We seek to address this issue by focusing on additional growth measures that incorporate sales, ${ }^{2}$ an important value driver for virtually any firm and the top line of an income statement (Penman 2001), and net operating assets (hereafter, NOA), a crucial component of equity value (Ohlson 1995; Feltham \& Ohlson 1995).

Additionally, examining the association between changes in special items and future firm growth may provide information incremental to that contained in fundamental signals documented in the literature (e.g., Lev \& Thiagarajan 1993; Abarbanell \& Bushee 1997). While these fundamental signals mainly refer to disproportionate changes in financial statement items related to sustainable earnings, we shift the focus to changes in presumably unsustainable components of earnings, i.e., special items. Just as unexpected changes in sustainable components of earnings aid in the prediction of future earnings and growth, both expected and unexpected changes in unsustainable components may also be helpful in that prediction. In this sense, changes in special items can be identified as an additional fundamental signal, as alluded, but not examined, by Nissim (2006).

Our empirical analysis not only shows the predictive content of changes in special items for future firm growth, but it also reveals asymmetric patterns in the relations between changes in special items and future firm growth. Specifically, regarding the earning effect of special items, we confirm that a decrease in special items reverses almost completely through one-year-ahead earnings, whereas an increase in special items is positively associated with the next year's earnings growth. This finding suggests a U-shaped relation between changes in special items and future earnings growth. Additionally, we find that the information embedded in changes in special items is incremental to that of fundamental signals documented in the literature, thereby identifying changes in special items as an additional fundamental signal.

More importantly, we find that both an increase and a decrease in special items lead to a decline in future sales and NOA, suggesting an inverse U-shaped relation between changes in special items and growth in these measures. A decrease in special items followed by a decline in future sales and NOA implies that more negative special items than in the previous year may signal a decline in future performance. ${ }^{3}$ On the other hand, an increase in special items also leads to a decline in future sales and NOA, possibly because less negative special items than in the previous year reflect a firm's negligence in terms of removing assets being used inefficiently. In stark contrast to the Ushaped relation between changes in special items and future earnings growth, the results for future sales and NOA growth underscore the importance of considering various growth measures in understanding the implication of changes in special items for future performance.

This paper makes several contributions to the literature. First, the paper contributes to the literature on the implications of special items for future firm performance (e.g., Burgstahler et al. 2002; Fairfield et al. 1996, 2009). While this line of literature focusses on the relations between levels of special items (especially, large negative special items) and future firm performance, our focus on changes in special items provides a more complete picture of such relations by incorporating small and/or positive special items that have been generally excluded from prior research. Second, to our knowledge, this study is one of the few that examine the relation between special items and net operating assets, the latter of which are a crucial component of equity value. Finally, by providing empirical evidence suggesting that changes in special items are an additional fundamental signal, this study contributes to the literature on fundamental analysis (e.g., Lev \& Thiagarajan 1993; Abarbanell \& Bushee 1997). Accordingly, our findings can be used practically for various types of decisions made by the users of financial statement information such as investors and analysts.

The remainder of the paper is organized as follows: Section II provides backgrounds and predictions. Section III presents the research design and variable measurement. Section IV discusses the sample selection and descriptive statistics. Section V presents the empirical results. Section VI concludes.

\footnotetext{
${ }^{2}$ While growth in income before extraordinary items captures much investor interest, Chan, Kareski, and Lakonishok (2003) support the use of sales growth because, for the former, valid growth rates are unavailable in many cases where the base-year value is negative. Relatedly, Fairfield et al. (2009) focus on both earnings growth and sales growth in their analysis of the effect of special items on future operating performance.

${ }^{3}$ See Section II for examples of negative special items.
} 


\section{BACKGROUND AND PREDICTIONS}

The main objective of this study is to examine the effects of changes in special items on growth in future earnings, sales, and NOA. However, prior research provides a plethora of evidence that firms manage earnings, thereby making it difficult to articulate the earnings effect. Accordingly, we focus on the sales and NOA effects, while providing a discussion on the earnings effect in an auxiliary manner. Since understanding these effects requires an understanding of changes in special items, we start by discussing the implications of changes in special items for future operating performance.

Special items can take negative or positive values. Examples of negative special items include restructuring costs (defined as one-time charges resulting from corporate restructurings), write-offs of receivables, inventories, equipment, or intangibles (including goodwill), and losses from sales of equipment. These activities are typical for poorly performing firms. Positive special items consist primarily of gains on sales of equipment and investments. Thus, negative and positive special items may not be fundamentally different from each other in terms of the underlying transactions they reflect. That is, special items are generally indicative of firms' poor operating performance.

Changes in special items, of course, consist of a decrease and an increase in special items. For clarification, we mean that a decrease in special items occurs when negative special items are more negative or when positive special items are less positive than in the previous period. In contrast, an increase in special items occurs when negative special items are less negative or when positive items are more positive than in the previous period. Since negative special items are substantially larger in absolute magnitudes and more frequent than positive special items, we focus on the implications of changes in negative special items for future operating performance.

As to a decrease in special items, this scenario generally occurs when negative special items, such as restructuring costs, write-offs, and losses on sale, are more negative than in the previous period. In terms of implications for future performance, two competing possibilities arise here. On one hand, negative special items are, by definition, indicative of a decline in a firm's future performance, and, as a result, more negative special items may lead to a decline in future sales and NOA. On the other hand, to the extent that these items reflect a reduction in inefficient use of assets, future performance may improve as a result of taking more negative special items than before. While an improvement in performance in this case may well be manifested as an increase in future earnings, a potential increase in future NOA and sales is less likely to occur unless the firm invests in alternative, revenue-generating operating assets, such as inventory and fixed assets.

Turning to an increase in special items, this scenario generally occurs when the aforementioned negative special items are less negative than in the previous period. Again, two competing possibilities arise here. On one hand, less negative special items than previously might signal a potential improvement in the firm's performance. On the other hand, less negative special items may reflect a firm's negligence in terms of removing assets being used inefficiently, thereby leading to a decline in future NOA and sales.

Taken together, for both a decrease and an increase in special items, two competing scenarios are applicable in terms of their effects on future performance. Since we have no prior as to which scenario will be dominant, it remains an empirical question as to how changes in special items will be associated with growth in future earnings, sales, and NOA.

\section{RESEARCH DESIGN}

To examine the relation between changes in special items and future firm growth, we first separate earnings into two components by subtracting after-tax special items (SI) from income before extraordinary items $(\mathrm{E}):^{4} \mathrm{E}=\mathrm{EBSI}+\mathrm{SI}$, where EBSI represents earnings before special items. We regress future firm growth measures on changes (denoted as " $\Delta$ ") in these two earnings components. In addition, we incorporate asymmetric effects of earnings components

\footnotetext{
${ }^{4}$ We calculate after-tax special items as special items provided by Compustat multiplied by $(1-$ marginal tax rate). The marginal tax rate is measured as in Nissim and Penman (2001). 
by including slope dummy variables that distinguish between an increase and a decrease in those components, resulting in the following regression model:

$$
G=\beta_{0}+\beta_{1} \Delta S I_{t}+\beta_{2} D S I_{t}+\beta_{3} \Delta S I_{t} * D S I_{t}+\beta_{4} \Delta E B S I_{t}+\beta_{5} D E B S I_{t}+\beta_{6} \Delta \mathrm{EBSI}_{t} * D E B S I_{t}+\varepsilon_{t+1}
$$

where $G$ is a firm-specific indicator of future growth, measured as EBSI for year $t+1$ minus EBSI for year $t$, deflated by the market value of equity at the end of year $t\left(\triangle E B S I_{t+1}\right),{ }^{5}$ sales growth for year $t+1\left(\triangle S A L E S_{t+1}\right)$, or growth in net operating assets for year $t+1\left(\triangle N O A_{t+1}\right)$. $D S I$ is an indicator variable that equals 1 when $\triangle S I$ is negative, and 0 otherwise. Similarly, $D E B S I$ is an indicator variable that equals 1 when $\triangle E B S I$ is negative, and 0 otherwise. Variables are defined in the Appendix.

Equation (1) provides the basis for the test of asymmetric effects of special items. ${ }^{6}$ The coefficient on $\Delta S I\left(\beta_{I}\right)$ captures the effect of an increase in special items on future firm growth, whereas $\beta_{1}+\beta_{3}$ reflects the effect of a decrease in special items on future growth. If an increase in special items is associated with an increase (decrease) in future firm growth, $\beta_{3}$ will be positive (negative). Also, if a decrease in special items is associated with an increase (decrease) in future firm growth, $\beta_{1}+\beta_{3}$ will be negative (positive).

While changes in special items may help predict future operating performance, prior research has suggested other fundamental signals that are also informative about future earnings growth. Those fundamental signals are usually identified as unexpected changes in sustainable components of earnings, whereas changes in special items can be interpreted as total changes in (presumably) unsustainable components of earnings. Thus, it is natural to ask whether changes in special items predict future earnings growth even after controlling for the effects of other fundamental signals that are mainly related to sustainable earnings. To explore this possibility, in equation (1) that uses future earnings growth as the dependent variable, we control for fundamental signals documented in the literature, as follows:

$$
\begin{aligned}
& \Delta E B S I_{t+1}=\beta_{0}+\beta_{1} \Delta S I_{t}+\beta_{2} D S I_{t}+\beta_{3} \Delta S I_{t} * D S I_{t}+\beta_{4} \Delta E B S I_{t}+\beta_{5} D E B S I_{t}+\beta_{6} \Delta E B S I_{t} * D E B S I_{t} \\
& +\Sigma \lambda_{k} S_{I S N A L_{k t}}+\varepsilon_{t+1}
\end{aligned}
$$

where $S I G N A L_{k t}$ is fundamental signal $k$ for year $t$. Based on the literature on fundamental analysis (e.g., Lev \& Thiagarajan 1993; Abarbanell \& Bushee 1997; Beneish 1999; Anderson, Banker, Huang \& Janakiraman, 2007), we consider the following nine fundamental signals: (1) inventory; (2) accounts receivable; (3) capital expenditure; (4) selling, general, and administrative (SG\&A) expenses, decomposed into positive and negative changes in SG\&A expenses; (5) effective tax rate; (6) labor force; (7) earnings quality; (8) audit quality; and (9) asset quality. ${ }^{7}$ For ease of interpretation, these signals are calculated so that the association between each signal and future earnings growth is negative. The measurement of each fundamental signal is described in the Appendix.

For the analysis of other growth measures, i.e., $\triangle S A L E S_{t+l}$ and $\triangle N O A_{t+l}$, we control for the serial correlation in each of these variables by including the corresponding value for year $t$ as follows:

$$
\begin{aligned}
& \Delta S A L E S_{t+1}=\beta_{0}+\beta_{1} \Delta S I_{t}+\beta_{2} D S I_{t}+\beta_{3} \Delta S I_{t} * D S I_{t}+\beta_{4} \Delta E B S I 2_{t}+\beta_{5} D E B S I 2_{t}+\beta_{6} \Delta E B S I 2_{t} * \\
& D E B S I 2_{t}+\beta_{7} \Delta \text { SALES }_{t}+\varepsilon_{t+1} \\
& \Delta N O A_{t+1}=\beta_{0}+\beta_{1} \Delta S I_{t}+\beta_{2} D S I_{t}+\beta_{3} \Delta S I_{t} * D S I_{t}+\beta_{4} \Delta E B S I_{t}+\beta_{5} D E B S I_{t}+\beta_{6} \Delta E B S I_{t} * D E B S I_{t} \\
& +\beta_{7} \Delta N O A_{t}+\varepsilon_{t+1}
\end{aligned}
$$

\footnotetext{
${ }^{5}$ A similar scaling method is used in Abarbanell and Bushee (1997).

${ }^{6}$ Including a slope dummy variable only for $\Delta S I$ may bias the results in favor of finding asymmetric effects of changes in special items. Thus, we allow asymmetry for changes in EBSI as well.

${ }^{7}$ Other fundamental signals include R\&D, provision for doubtful receivables, and order backlog, all of which are excluded from our analysis to avoid a large loss of observations. Also, we do not use changes in gross margin because this signal is a component of changes in EBSI that are an independent variable in our regression model.
} 
where the additional independent variables, $\triangle S A L E S_{t}$ and $\triangle N O A_{t}$, represent sales growth and growth in NOA for year $t$, respectively. In equation (2b), since we use sales growth for year $t$ as an additional explanatory variable, we subtract sales from EBSI. We denote the resulting variable as EBSI2 and define $\triangle E B S I 2$ and DEBSI2 similarly to $\triangle E B S I$ and $D E B S I$, respectively. In each of equations (2a), (2b), and (2c), the coefficients of interest are still $\beta_{1}$ and $\beta_{1}+\beta_{3}$, as described above.

\section{SAMPLE AND DESCRIPTIVE STATISTICS}

We obtain data for fiscal years 1974 2014 from Compustat. We exclude the firm-years that had a fiscal-year-end change to help ensure that fiscal years are comparable. We also exclude the firm-year observations that do not have total assets, income before extraordinary items, price per share, and the number of shares outstanding. In addition, each firm-year observation is required to have sufficient data to calculate fundamental signals. Also, firms in the financial industries are excluded because the separation of their operating and financial activities is arbitrary and thus leads to misleading calculations of NOA. These requirements are commonly imposed in previous research.

We rely on Compustat's classification of special items. However, unlike prior studies that generally include only material special items, we do not exclude non-material special items because our focus is on changes in special items. Finally, to mitigate the effect of outliers, we winsorize all continuous variables at the top and bottom $1 \%$.

Table 1 describes the sample selection procedure. The initial sample with non-missing special items consists of 204,604 firm-year observations representing 21,692 firms. Of these observations, special items are negative for 32.1\% and positive for $12.7 \%$, indicating that negative special items are more prevalent than positive special items, as in previous research. In contrast, the portion of increases in special items $(28.1 \%)$ is slightly lower than that of decreases in special items $(30.1 \%)$. Requiring data to compute fundamental signals reduces the sample to 54,872 observations representing 9,025 firms. Imposing non-missing data on growth in future earnings, sales, or NOA results in a final sample of 47,441 firm-years representing 8,055 firms. In the final sample, the aforementioned portions related to levels of and changes in special items remain similar.

Table 1. Sample Selection

\begin{tabular}{|c|c|c|c|c|c|c|c|c|}
\hline & $\begin{array}{l}\text { Number of } \\
\text { Firm-years }\end{array}$ & $\begin{array}{l}\text { Number } \\
\text { of Firms }\end{array}$ & $\mathbf{S I}=\mathbf{0}$ & $\mathrm{SI}>\mathbf{0}$ & $\mathrm{SI}<\mathbf{0}$ & $\Delta \mathbf{S I}=\mathbf{0}$ & $\Delta \mathrm{SI}>\mathbf{0}$ & $\Delta \mathbf{S I}<\mathbf{0}$ \\
\hline $\begin{array}{l}\text { 1974-2014 with necessary Compustat } \\
\text { data satisfying the requirements }\end{array}$ & 283,379 & 23,486 & & & & & & \\
\hline \multirow[t]{2}{*}{$\begin{array}{l}\text { Less: Data missing changes in special } \\
\text { items }\end{array}$} & 33,775 & 1,794 & & & & & & \\
\hline & 204,604 & 21,692 & $55.2 \%$ & $12.7 \%$ & $32.1 \%$ & $41.8 \%$ & $28.1 \%$ & $30.1 \%$ \\
\hline \multirow[t]{2}{*}{$\begin{array}{l}\text { Less: Data to compute fundamental } \\
\text { signals unavailable }\end{array}$} & 149,732 & 12,667 & & & & & & \\
\hline & 54,872 & 9,025 & $56.3 \%$ & $12.0 \%$ & $31.7 \%$ & $44.5 \%$ & $26.8 \%$ & $28.7 \%$ \\
\hline $\begin{array}{l}\text { Less: Data missing dependent } \\
\text { variables }\end{array}$ & 7,431 & 970 & & & & & & \\
\hline Final sample & 47,441 & 8,055 & $57.9 \%$ & $11.7 \%$ & $30.4 \%$ & $46.0 \%$ & $26.3 \%$ & $27.7 \%$ \\
\hline
\end{tabular}

*We exclude the firm-year observations that: (1) had a fiscal-year-end change from year $t-1$ to $t$; (2) do not have total assets, income before extraordinary items, price per share, and the number of shares outstanding; and (3) fall in the financial industry (SIC 6000s).

SI means special items and $\Delta$ SI mean changes in special items.

Table 2 provides descriptive statistics for the variables used in our analysis. Regarding earnings growth measures, $\triangle E_{t+1}$ and $\triangle E B S I_{t+1}$ have a mean of 0.037 and 0.030 , respectively. For other growth measures, $\triangle S A L E S_{t+1}$ and $\triangle N O A_{t+1}$ have a mean of 0.092 and 0.109 , respectively. Turning to independent variables, we note that $D E B S I_{t}$ has a mean of 0.409 , meaning that more than $40 \%$ of firm-years experienced decreases in earnings before special items. The descriptive statistics for fundamental signals are generally consistent with prior research. 
Table 2. Descriptive Statistics

\begin{tabular}{|c|c|c|c|c|c|}
\hline Variable & Mean & Median & SD & Q1 & Q3 \\
\hline \multicolumn{6}{|l|}{ Dependent Variables: } \\
\hline$\Delta E B S I_{t+1}$ & 0.030 & 0.008 & 0.303 & -0.032 & 0.048 \\
\hline$\triangle S A L E S_{t+1}$ & 0.092 & 0.072 & 0.286 & -0.040 & 0.192 \\
\hline$\Delta N O A_{t^{+1}}$ & 0.109 & 0.046 & 0.561 & -0.080 & 0.203 \\
\hline \multicolumn{6}{|l|}{ Independent Variables: } \\
\hline$\Delta S I_{t}$ & 0.005 & 0.000 & 0.098 & -0.001 & 0.001 \\
\hline$D S I_{t}$ & 0.277 & 0.000 & 0.447 & 0.000 & 1.000 \\
\hline$\Delta E B S I_{t}$ & 0.030 & 0.008 & 0.265 & -0.030 & 0.049 \\
\hline$D E B S I_{t}$ & 0.409 & 0.000 & 0.492 & 0.000 & 1.000 \\
\hline \multicolumn{6}{|l|}{ Fundamental Signals: } \\
\hline$I N V_{t}$ & 0.028 & -0.008 & 0.420 & -0.128 & 0.117 \\
\hline$A R_{t}$ & 0.002 & -0.008 & 0.247 & -0.098 & 0.082 \\
\hline$C A P X_{t}$ & 0.183 & 0.025 & 0.747 & -0.187 & 0.298 \\
\hline$P S G A_{t}$ & 0.055 & 0.003 & 0.174 & 0.000 & 0.061 \\
\hline$N S G A_{t}$ & -0.078 & 0.000 & 0.636 & -0.057 & 0.000 \\
\hline$E T R_{t}$ & -0.006 & 0.000 & 0.123 & -0.003 & 0.001 \\
\hline$L F_{t}$ & -0.090 & -0.054 & 0.292 & -0.163 & 0.040 \\
\hline$E Q_{t}$ & 0.840 & 1.000 & 0.367 & 1.000 & 1.000 \\
\hline$A U D I T_{t}$ & 0.274 & 0.000 & 0.446 & 0.000 & 1.000 \\
\hline$A Q_{t}$ & 0.039 & -0.004 & 0.326 & -0.081 & 0.084 \\
\hline
\end{tabular}

SD, Q1, and Q3 represent the standard deviation, the first quartile, and the third quartile, respectively. See Appendix for variable definitions.

\section{EMPIRICAL RESULTS}

Table 3 presents the results for regressions of future earnings growth on changes in special items. The results are reported in two columns, representing the results for equations (1) and (2a), respectively. For all regressions in this study, we include year and industry indicators, and t-statistics are calculated based on standard errors clustered at the firm level.

Regarding the results for equation (1), we confirm the asymmetric effects of changes in special items on future earnings growth. Specifically, the coefficient $\left(\beta_{l}\right)$ on changes in SI $\left(\Delta S I_{t}\right)$ is significantly positive (coeff. $=0.137$, pvalue $<0.01$ ), and the sum of the coefficients on $\Delta S I_{t}$ and $\Delta S I_{t}^{*} D S I_{t}\left(\beta_{1}+\beta_{3}\right)$ is significantly negative (coeff. = 0.750 , p-value $<0.01$ ). In particular, the latter result indicates that a decrease in special items leads to an improvement in the next year's earnings, consistent with the reversal of special items documented in the literature (e.g., Burgstahler et al. 2002). Taken together, our findings suggest that both an increase and a decrease in special items are accompanied by an improvement in future earnings, implying a U-shaped relation between changes in special items and future earnings growth.

In addition, we find that the coefficient on changes in EBSI $\left(\triangle E B S I_{t}\right)$ is positive but insignificant, whereas the coefficient on $\triangle E B S I_{t}{ }^{*} D E B S I_{t}$ is strongly negative. This implies that changes in EBSI exhibit a negative serial correlation, which is driven by decreases in EBSI that partially reverse in the following year.

Regarding the results for equation (2a), we find that the above results hold after controlling for the effects of fundamental signals on future earnings growth. In particular, we continue to find the aforementioned U-shaped relation between changes in special items and growth in future earnings before special items. In addition, the results for fundamental signals are generally consistent with those reported in related studies. ${ }^{8}$ These results suggest that changes in special items can be viewed as an additional fundamental signal.

\footnotetext{
${ }^{8}$ Contrary to the prediction, the coefficient on CAPX is significantly positive, but Abarbanell and Bushee (1997) also report a similar result.
} 
Table 3. Regressions of Future Earnings Growth on Changes in Special Items

\begin{tabular}{|c|c|c|c|c|c|c|c|}
\hline \multirow{2}{*}{ Variable } & \multirow{2}{*}{ Coeff. } & \multicolumn{3}{|c|}{ Equation (1) } & \multicolumn{3}{|c|}{ Equation (2a) } \\
\hline & & Estimate & \multicolumn{2}{|r|}{ t-stat. } & Estimate & \multirow{2}{*}{\multicolumn{2}{|c|}{2.95}} \\
\hline$\Delta S I_{t}$ & $\beta_{1}$ & $0.137^{* * *}$ & \multicolumn{2}{|c|}{3.14} & $0.129^{* * *}$ & & \\
\hline$D S I_{t}$ & & 0.000 & \multicolumn{2}{|c|}{0.06} & -0.000 & \multicolumn{2}{|c|}{-0.07} \\
\hline$\Delta S I_{t} * D S I_{t}$ & $\beta_{3}$ & $-0.887^{* * *}$ & \multicolumn{2}{|c|}{-10.86} & $-0.835^{* * *}$ & \multicolumn{2}{|c|}{-10.20} \\
\hline$\triangle E B S I_{t}$ & & 0.020 & \multicolumn{2}{|c|}{1.14} & 0.001 & \multicolumn{2}{|r|}{0.04} \\
\hline$D E B S I_{t}$ & & $-0.038^{* * *}$ & \multicolumn{2}{|c|}{-12.45} & $-0.034^{* * *}$ & \multicolumn{2}{|c|}{-10.93} \\
\hline$\triangle E B S I_{t}^{*} D E B S I_{t}$ & & $-0.776^{* * *}$ & \multicolumn{2}{|c|}{-20.63} & $-0.737^{* * *}$ & \multicolumn{2}{|c|}{-19.49} \\
\hline$I N V_{t}$ & & & & & $-0.008^{* *}$ & & 2.37 \\
\hline$A R_{t}$ & & & & & $-0.025^{* * *}$ & & 3.63 \\
\hline$C A P X_{t}$ & & & & & $0.025^{* * *}$ & & 8.01 \\
\hline$P S G A_{t}$ & & & & & 0.016 & & 1.13 \\
\hline$N S G A_{t}$ & & & & & $0.010^{* * *}$ & & 3.43 \\
\hline$E^{E T R_{t}}$ & & & & & $-0.069^{* * *}$ & & 2.95 \\
\hline$L F_{t}$ & & & & & $-0.044^{* * *}$ & & 5.67 \\
\hline$E Q_{t}$ & & & & & 0.000 & & 0.04 \\
\hline$A U D I T_{t}$ & & & & & $-0.011^{* * *}$ & & 3.34 \\
\hline$A Q_{t}$ & & & & & -0.006 & & 1.53 \\
\hline \multicolumn{2}{|c|}{ Year \& industry indicators } & \multicolumn{3}{|c|}{ Included } & \multicolumn{3}{|c|}{ Included } \\
\hline \multicolumn{2}{|c|}{ Adjusted $\mathrm{R}^{2}$} & \multicolumn{3}{|c|}{0.141} & \multicolumn{3}{|c|}{0.148} \\
\hline \multirow{2}{*}{\multicolumn{2}{|c|}{ F-test for $\beta_{1}+\beta_{3}=0$}} & Estimate & F-stat. & p-value & Estimate & & p-value \\
\hline & & $-0.750^{* * *}$ & 122.98 & $<0.01$ & $-0.706^{* * *}$ & & $<0.01$ \\
\hline
\end{tabular}

$* * *, * *, *$ denotes significance at the 1,5 , and 10 percent levels (two-tailed), respectively.

This table presents the results for regressions of future earnings growth on changes in special items. See Appendix for variable definitions. Tstatistics are calculated based on standard errors clustered at the firm level.

Table 4 presents the results for regressions of future sales growth on changes in special items. We report the results in two columns, excluding and including the control for current sales growth, respectively. In both columns, the results indicate that the coefficient $\left(\beta_{l}\right)$ on changes in SI $\left(\Delta S I_{t}\right)$ is significantly negative, whereas the sum of the coefficients on $\Delta S I_{t}$ and $\Delta S I_{t} * D S I_{t}\left(\beta_{1}+\beta_{3}\right)$ is significantly positive. That is, both an increase and a decrease in special items lead to a decline in the next year's sales.

Table 4. Regressions of Future Sales Growth on Changes in Special Items

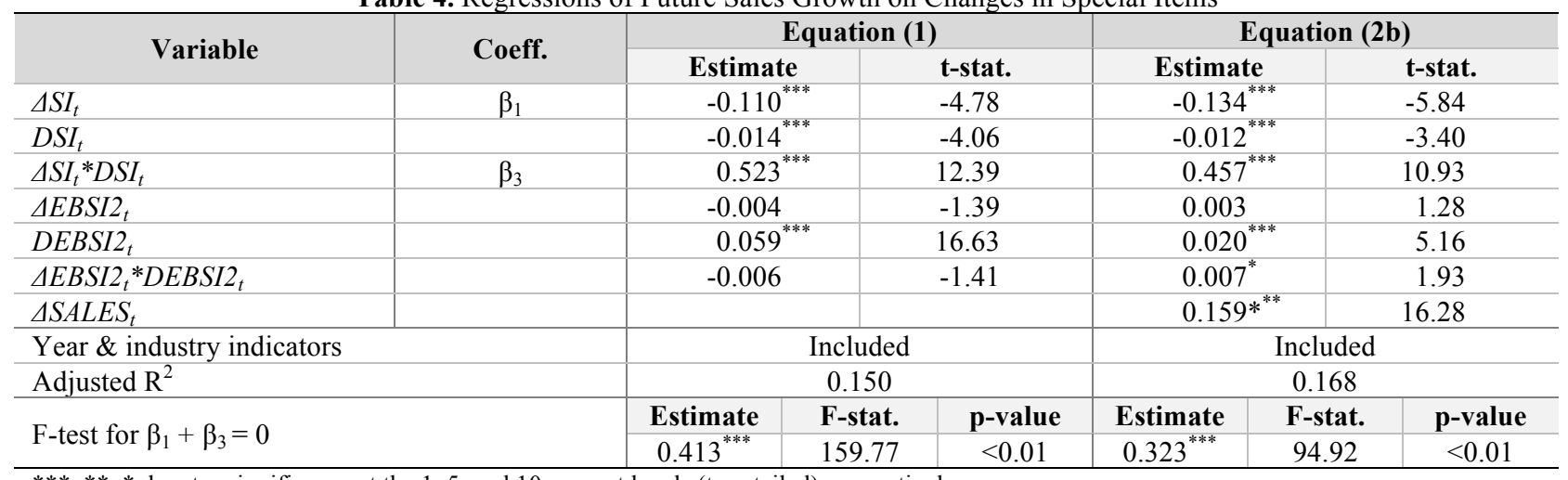

$* * *, * *, *$ denotes significance at the 1,5 , and 10 percent levels (two-tailed), respectively.

This table presents the results for regressions of future sales growth on changes in special items. $\triangle E B S I 2_{t}$ is defined as changes in EBSI for year $t$ minus changes in sales for year $t$, divided by the market value of equity at the end of year $t-1$. DEBSI2 ${ }_{t}$ is an indicator variable that equals 1 when $\triangle E B S I 2_{t}$ is negative, and 0 otherwise. See Appendix for the definitions of other variables. T-statistics are calculated based on standard errors clustered at the firm level. 
Table 5 provides the results for regressions of growth in future NOA on changes in special items. The results are similar to those reported in Table 4. Specifically, in both specifications without and with control for current NOA growth, the coefficient on $\Delta S I_{t}$ is significantly negative, whereas the sum of the coefficients on $\Delta S I_{t}$ and $\Delta S I_{t}{ }^{*} D S I_{t}$ is significantly positive. Thus, both an increase and a decrease in special items result in a decline in the next year's NOA.

Table 5. Regressions of Growth in Future Net Operating Assets on Changes in Special Items

\begin{tabular}{|c|c|c|c|c|c|c|c|}
\hline \multirow{2}{*}{ Variable } & \multirow{2}{*}{ Coeff. } & \multicolumn{3}{|c|}{ Equation (1) } & \multicolumn{3}{|c|}{ Equation (2c) } \\
\hline & & Estimate & \multicolumn{2}{|c|}{ t-stat. } & Estimate & \multicolumn{2}{|r|}{ t-stat. } \\
\hline$\Delta S I_{t}$ & $\beta_{1}$ & $-0.350^{* * *}$ & \multicolumn{2}{|c|}{-6.86} & $-0.340^{* * *}$ & \multicolumn{2}{|r|}{-6.65} \\
\hline$D S I_{t}$ & & $-0.017^{* *}$ & \multicolumn{2}{|c|}{-2.38} & $-0.017^{* *}$ & \multicolumn{2}{|r|}{-2.43} \\
\hline$\Delta S I_{t} * D S I_{t}$ & $\beta_{3}$ & $0.640^{* * *}$ & \multicolumn{2}{|c|}{6.95} & $0.609^{* * *}$ & \multicolumn{2}{|r|}{6.61} \\
\hline$\triangle E B S I_{t}$ & & $-0.081^{* * *}$ & \multicolumn{2}{|c|}{-4.06} & $-0.078^{* * *}$ & \multicolumn{2}{|r|}{-3.94} \\
\hline$D E B S I_{t}$ & & $-0.108^{* * *}$ & \multicolumn{2}{|c|}{-17.61} & $-0.107^{* * *}$ & \multicolumn{2}{|r|}{-17.38} \\
\hline$\Delta E B S I_{t}^{*} D E B S I_{t}$ & & \multirow[t]{2}{*}{$0.368^{* * *}$} & \multicolumn{2}{|c|}{9.44} & $0.356^{* * *}$ & \multicolumn{2}{|r|}{9.14} \\
\hline$\triangle N O A_{t}$ & & & & & $0.025^{* * *}$ & & 2.80 \\
\hline \multicolumn{2}{|c|}{ Year \& industry indicators } & \multicolumn{3}{|c|}{ Included } & \multicolumn{3}{|c|}{ Included } \\
\hline \multicolumn{2}{|c|}{ Adjusted $\mathrm{R}^{2}$} & \multicolumn{3}{|c|}{0.067} & \multicolumn{3}{|c|}{0.068} \\
\hline \multirow{2}{*}{\multicolumn{2}{|c|}{ F-test for $\beta_{1}+\beta_{3}=0$}} & Estimate & F-stat. & p-value & Estimate & F-stat. & p-value \\
\hline & & $0.413^{* * *}$ & 13.72 & $<0.01$ & $0.323^{* * *}$ & 11.78 & $<0.01$ \\
\hline
\end{tabular}

***,**,* denotes significance at the 1,5 , and 10 percent levels (two-tailed), respectively.

This table presents the results for regressions of growth in future net operating assets on changes in special items. See Appendix for variable definitions. T-statistics are calculated based on standard errors clustered at the firm level.

Taken together, the results reported in Tables 4 and 5 suggest an inverse U-shaped relation between changes in special items and growth in future sales and NOA. A decrease in special items associated with a decline in future sales and NOA implies that more negative special items (such as restructuring costs, write-offs, and losses on sale) than in the previous year are indicative of a decline in future performance, consistent with the definition of negative special items. On the other hand, an increase in special items also results in a decline in future sales and NOA, possibly because less negative special items than in the previous year reflect a firm's negligence in terms of removing assets being used inefficiently. These results are in stark contrast to the U-shaped relation between changes in special items and future earnings growth, as reported in Table 3, which can be explained primarily by the reversal in special items through future earnings. In this sense, the results for future sales and NOA growth highlight the importance of considering various growth measures in understanding the implication of changes in special items for future performance.

\section{CONCLUSION}

This paper investigates the implication of changes in special items for growth in future earnings, sales, and NOA. Our empirical results indicate that a decrease in special items exhibits a negative association with the next year's earnings growth, whereas an increase in special items shows a positive association, suggesting a U-shaped relation between changes in special items and future earnings growth. Additionally, the results indicate that the information contained in changes in special items is incremental to that of fundamental signals documented in the literature. Furthermore, we find that both an increase and a decrease in special items lead to a decline in future sales and net operating assets, suggesting an "inverse U-shaped relation" between changes in special items and growth in these measures. Overall, our findings underscore the importance of considering a variety of growth measures in understanding how changes in special items affect future firm growth.

Our findings offer several avenues for future research. For example, future research could explore whether the asymmetric persistence of special items is associated with analysts' forecasts revisions in the same way that it is related to future earnings growth. Furthermore, given the importance of sales and NOA in evaluating equity value, future research could also examine how to incorporate the asymmetric effects of changes in special items in accounting-based valuation models. 


\section{AUTHOR BIOGRAPHIES}

Young Zik Shin is a Ph.D. student in Accounting at Sungkyunkwan University, South Korea. Prior to joining the $\mathrm{Ph} . \mathrm{D}$. program, he worked at Samsung R\&T, a real estate investment company. His research interests include earnings management, corporate governance, and market reaction to accounting information.

Yong Gyu Lee (corresponding author) is an Associate Professor of Accounting at Sungkyunkwan University, South Korea. He received his Ph.D. from Columbia University, USA. His research interests include earnings management, managerial incentives, and economic consequences of financial reporting and regulation.

\section{REFERENCES}

Abarbanell, J. \& Bushee, B. (1997). Fundamental analysis, future earnings and stock prices. Journal of Accounting Research, $35(1), 1-24$

Anderson, M., Banker, R., Huang, R. \& Janakiraman, R. (2007). Cost behavior and fundamental analysis of SG\&A costs. Journal of Accounting, Auditing and Finance, 22(1), 1-28.

Beneish, D. (1999). The detection of earnings manipulation. Financial Analysts Journal, 55(5), 24-36.

Burgstahler, D., Jiambalvo, J. \& Shevlin, T (2002). Do stock prices fully reflect the implications of special items for future earnings? Journal of Accounting Research, 40(3), 585-612.

Chan, L., Karceski, J. \& Lakonishok, J. (2003). The level and persistence of growth rates. Journal of Finance, 58(2), 643-684.

Cready, W., Lopez, T. \& Sisneros, C. (2010). The persistence and market valuation of recurring nonrecurring items. The Accounting Review, 85(5), 1577-1615.

Elliott, J. \& Hanna, J. (1996). Repeated accounting write-offs and the information content of earnings. Journal of Accounting Research, 34 (Supplement), 135-155.

Fairfield, P., Kitching, K. \& Tang, V. (2009). Are special items informative about future profit margins? Review of Accounting Studies, 14(2), 204-236.

Fairfield, P., Sweeney, R. \& Yohn, T. (1996). Accounting classification and the predictive content of earnings. The Accounting Review, 71(3), 337-355.

Feltham, J. \& Ohlson, J. (1995). Valuation and clean surplus accounting for operating and financial activities. Contemporary Accounting Research, 11(2), 689-731.

Frankel, R. \& Roychowdhury, S. (2007). Predicted asymmetric timeliness and the persistence of special items. Working paper, Washington University and MIT.

Kinney, M. \& Trezevant, R. (1997). The use of special items to manage earnings and perceptions. Journal of Financial Statement Analysis, 3(1), 45-53.

Lev, B. \& Thiagarajan, S. (1993). Fundamental information analysis. Journal of Accounting Research, 31, (2): $190-215$.

McVay, S. (2006). Earnings management using classification shifting: An examination of core earnings and special items. The Accounting Review, 81(3), 501-531.

Nissim, D. (2006). Forecasting earnings. Presentation at the Center for Accounting Research and Education Conference on Financial Statement Analysis and Valuation, University of Notre Dame.

Nissim, D. \& Penman, S. (2001). Ratio analysis and equity valuation: From research to practice. Review of Accounting Studies, 6(1), 109-154.

Ohlson, J. (1995). Earnings, book values, and dividends in equity valuation, Contemporary Accounting Research, 11(2), 661687.

Penman, S. (2001). Discussion of 'Back to basics: Forecasting the revenues of internet firms' and 'A rude awakening: Internet shakeout in 2000.' Review of Accounting Studies, 6(2/3), 361-364.

Revsine, L., Collins, D. \& Johnson, W. (2005). Financial reporting and analysis. Upper Saddle River, NJ. USA: Prentice Hall. 
Appendix. Variable Definitions

\begin{tabular}{|c|c|c|}
\hline Variable & & Measurement \\
\hline \multicolumn{3}{|c|}{ Dependent variables } \\
\hline$\Delta E B S I_{t+1}$ & $=$ & $\begin{array}{l}\text { EBSI for year } t+1 \text { minus EBSI for year } t \text {, deflated by the market value of equity at the end of year } t \text {, where } \\
\text { EBSI represents earnings before special items }\end{array}$ \\
\hline$\triangle S A L E S_{t+1}$ & $=$ & Sales growth for year $t+1$ \\
\hline$\Delta N O A_{t+1}$ & $=$ & $\begin{array}{l}\text { Growth in net operating assets }(\mathrm{NOA}) \text { for year } t+1 \text {, where } \mathrm{NOA}=\text { common equity }+ \text { financial obligations } \\
\text { (i.e., debt in current liabilities }+ \text { total long-term debt }+ \text { preferred stock) }- \text { financial assets (i.e., cash and } \\
\text { short-term investments }+ \text { investments) }+ \text { minority interest }\end{array}$ \\
\hline \multicolumn{3}{|c|}{ Independent variables } \\
\hline$\Delta S I_{t}$ & $=$ & $\begin{array}{l}\text { After-tax special items }(S I) \text { for year } t \text { minus } S I \text { for year } t-1 \text {, deflated by the market value of equity at the } \\
\text { end of year } t-1 \text {, where } S I=\text { special items (provided by Compustat), multiplied by }(1-\text { marginal tax rate). } \\
\text { The marginal tax rate is measured as in Nissim and Penman (2001). }\end{array}$ \\
\hline$D S I_{t}$ & $=$ & An indicator variable that equals 1 when $\Delta S I_{t}$ is negative, and 0 otherwise \\
\hline$\triangle E B S I_{t}$ & $=$ & EBSI for year $t$ minus EBSI for year $t-1$, deflated by the market value of equity at the end of year $t-1$ \\
\hline$D E B S I_{t}$ & $=$ & An indicator variable that equals 1 when $\triangle E B S I_{t}$ is negative, and 0 otherwise \\
\hline \multicolumn{3}{|c|}{$\begin{array}{l}\text { Fundamental signals (Notes: For each signal, the " } \% \Delta \text { " operator represents a percentage change in the variable from the average } \\
\text { of two previous years. All signals are measured for year } t \text {, unless specified otherwise.) }\end{array}$} \\
\hline$I N V_{t}$ & $=$ & $\begin{array}{l}\% \Delta \text { Inventory }-\% \Delta \text { Sales, where the inventory variable is finished goods when available, and total } \\
\text { inventory otherwise }\end{array}$ \\
\hline$A R_{t}$ & $=$ & $\% \Delta$ Accounts Receivable $-\% \Delta$ Sales \\
\hline$C A P X_{t}$ & $=$ & $\% \Delta$ Industry CAPX $-\% \Delta$ Firm CAPX, where CAPX represents capital expenditures \\
\hline$P S G A_{t}$ & $=$ & $\begin{array}{l}\text { An indicator variable that equals } \% \Delta \text { SGA }(189)-\% \Delta \text { Sales, when this variable is positive, and } 0 \\
\text { otherwise, where SGA represents SG\&A expenses }\end{array}$ \\
\hline$N S G A_{t}$ & $=$ & $\begin{array}{l}\text { An indicator variable that equals } \% \Delta \text { SGA }(189)-\% \Delta \text { Sales, when this variable is negative, and } 0 \\
\text { otherwise }\end{array}$ \\
\hline$E T R_{t}$ & $=$ & $\begin{array}{l}\left\{E\left(E T R_{t}\right)-E T R_{t}\right\} *\left(E_{t}-E_{t-1}\right) \text {, where } E T R_{t} \text { is the effective tax rate for year } t \text {, measured as tax expense } \\
\text { divided by earnings before tax, E(ETR }) \text { is the expected effective tax rate for year } t \text {, measured as the } \\
\text { average } E T R \text { for the prior three years, and } E_{t} \text { is earnings before extraordinary items for year } t \text {, deflated by } \\
\text { the market value of equity at the end of year } t-1\end{array}$ \\
\hline$L F_{t}$ & $=$ & $\begin{array}{l}\text { Labor force, measured as }\left(E M P_{t-1}-E M P_{t}\right) / E M P_{t-1} \text {, where } E M P_{t}=\text { sales divided by the number of } \\
\text { employees for year } t\end{array}$ \\
\hline$E Q_{t}$ & $=$ & $\begin{array}{l}\text { Earnings quality, measured as an indicator variable that equals } 0 \text { for LIFO, and } 1 \text { for FIFO and other } \\
\text { inventory methods }\end{array}$ \\
\hline$A U D I T_{t}$ & $=$ & An indicator variable that equals 0 for Big 4 , and 1 for non-Big 4 audit firms \\
\hline$A Q_{t}$ & $=$ & Asset quality, measured as $\% \Delta$ Non-current assets except PP\&E $-\% \Delta$ Assets \\
\hline
\end{tabular}

